\title{
Different Clinical Behaviors of Acute Hepatitis C Virus Infection Are Associated with Different Vigor of the Anti-viral Cell-mediated Immune Response
}

\author{
Gabriele Missale, ${ }^{\star}$ Roberto Bertoni, ${ }^{\star}$ Vincenzo Lamonaca, ${ }^{\star}$ Antonietta Valli, ${ }^{*}$ Marco Massari, ${ }^{\ddagger}$ Cristina Mori, ${ }^{\star}$ \\ Maria Grazia Rumi, $\$$ Michael Houghton, $\|$ Franco Fiaccadori, ${ }^{\star}$ Carlo Ferrari* \\ * Cattedra Malattie Infettive, Università di Parma, e Divisione Malattie Infettive e Immunopatologia Virale, Azienda Ospedaliera di \\ Parma, 43100, Parma; ${ }^{\ddagger}$ Divisione Malattie Infettive, Azienda Ospedaliera di Reggio Emilia, 42100, Reggio Emilia; ${ }^{\S}$ Cattedra di Medicina \\ Interna, Università di Milano, I.R.C.C.S. Ospedale Policlinico, 20122 Milano, Italy; ${ }^{\| C h i r o n ~ C o r p o r a t i o n, ~ E m e r y v i l l e, ~ C a l i f o r n i a ~} 94608-2916$
}

\begin{abstract}
The anti-viral $\mathrm{T}$ cell response is believed to play a central role in the pathogenesis of hepatitis $\mathrm{C}$ virus infection. Since chronic evolution occurs in $>50 \%$ of $\mathrm{HCV}$ infections, the sequential analysis of the $T$ cell response from the early clinical stages of disease may contribute to define the features of the $T$ cell response associated with recovery or chronic viral persistence. For this purpose, 21 subjects with acute hepatitis $C$ virus infection were sequentially followed for an average time of $44 \mathrm{wk}$. Twelve patients normalized transaminase values that remained normal throughout the follow-up period; all but two cleared hepatitis $C$ virus-RNA from serum. The remaining nine patients showed persistent viremia and elevated transaminases. Analysis of the peripheral blood $\mathrm{T}$ cell proliferative response to core, E1, E2, NS3, NS4, and NS5 recombinant antigens and synthetic peptides showed that responses to all hepatitis $\mathrm{C}$ virus antigens, except E1, were significantly more vigorous and more frequently detectable in patients who normalized transaminase levels than in those who did not. By sequential evaluation of the $T$ cell response, a difference between the two groups of patients was already detectable at the very early stages of acute infection and then maintained throughout the followup period. The results suggest that the vigor of the $T$ cell response during the early stages of infection may be a critical determinant of disease resolution and control of infection. (J. Clin. Invest. 1996. 98:706-714.) Key words: T cells • viremia $\bullet$ antigens $\bullet$ peptides $\bullet$ proliferative response
\end{abstract}

\section{Introduction}

The hepatitis $\mathrm{C}$ virus $(\mathrm{HCV})^{1}$ is an RNA virus that can cause acute self-limited infections and chronic hepatocellular injury with possible progression to cirrhosis and hepatocellular carcinoma (1). The mechanisms responsible for liver cell damage and for the high rate of viral persistence are still largely unknown.

Address correspondence to Carlo Ferrari, M.D., Cattedra di Malattie Infettive, Università di Parma, Via Gramsci 14, 43100 Parma, Italy. Phone: 39-521-991056; FAX: 39-521-988706.

Received for publication 27 February 1996 and accepted in revised form 17 May 1996.

1. Abbreviations used in this paper: ALT, alanine aminotransferase; APC, antigen-presenting cells; $\mathrm{HCV}$, hepatitis $\mathrm{C}$ virus.

J. Clin. Invest.

(C) The American Society for Clinical Investigation, Inc. 0021-9738/96/08/0706/09 \$2.00

Volume 98, Number 3, August 1996, 706-714
While the contribution of a direct cytopathic effect of HCV to liver damage is still controversial, several lines of indirect evidence, including the existence of chronic $\mathrm{HCV}$ infections without clinically overt disease (2) and the frequent association with autoimmune syndromes (3), indicate that immunemediated mechanisms are likely to play an important role in the pathogenesis of hepatitis $\mathrm{C}$. This is also suggested by the presence of CD4+ and CD8+ T cells able to recognize structural and nonstructural $\mathrm{HCV}$ antigens within the liver as well as in the peripheral blood of patients with chronic HCV infection (4-14). Why HCV can persist with high efficiency in the face of CD8- and CD4-mediated anti-viral $\mathrm{T}$ cell responses readily detectable in blood and liver and thus potentially favorable to $\mathrm{HCV}$ clearance is a central pathogenetic issue that remains to be addressed.

Most available data on cell-mediated immune responses come from patients with an already established condition of chronic infection (4-14), whereas only a single study has been carried out so far in patients with acute HCV infection suggesting that an efficient $\mathrm{T}$ cell response to NS3 and possibly to other nonstructural HCV proteins is critical for successful viral clearance (15).

To further characterize the $\mathrm{T}$ cell responses occurring in the initial stages of disease which are likely to be crucial for the final outcome of infection and to define the peculiar features of the $\mathrm{T}$ cell response which are specifically associated with recovery or chronic viral persistence, we studied the HLA class II-restricted proliferative $\mathrm{T}$ cell response to $\mathrm{HCV}$ proteins sequentially from the early clinical stages of disease in patients with different outcomes of infection. Results indicate a quantitative difference in the HLA class II-restricted T cell response to $\mathrm{HCV}$ antigens core, E2, NS3, NS4, and NS5 between patients with acute $\mathrm{HCV}$ infection who succeed in normalizing the biochemical parameters of disease activity and those who maintain elevated transaminase levels. This difference in the anti-viral T cell response may represent an important determinant of the final outcome of infection.

\section{Methods}

Patients. Twenty one patients with acute hepatitis C (18 males and 3 females; mean age, 30) were studied. Diagnosis of acute HCV infection was based on the finding of elevated values of serum alanine aminotransferase (ALT) at least 10 times the normal values, associated with anti-HCV antibody seroconversion by second-generation ELISA (ELISA II; Ortho Diagnostic Systems, Raritan NJ, which detects antibodies to core, NS3 and NS4) or by RIBA II (Ortho Diagnostic Systems) showing the appearance of antibodies to NS4 (in most cases) or NS3. Four patients were included in the study even though seroconversion was not observed, on the basis of their clinical behavior and anamnestic characteristics. Other possible causes of acute hepatitis (i.e., viruses, toxins, alcohol, autoimmunity, metabolic factors) were excluded. 
One of the patients with acute hepatitis was coinfected with hepatitis $B$ virus (HBV) and became hepatitis B surface antigen positive 2 mo after the transaminase peak caused by HCV. The remaining patients were negative for HBV markers. HCV-RNA was tested at the beginning of the disease confirming the HCV etiology.

Control experiments were performed on 12 healthy subjects with no evidence of previous exposure to $\mathrm{HCV}$ (i.e., they were negative for anti-HCV by second-generation ELISA).

The study was approved by the Ethics Committee of the University of Parma, and all patients gave informed consent before entering the study.

Qualitative and quantitative $H C V$-RNA determination. Sera were tested for qualitative HCV-RNA by a reverse transcription-nested PCR assay with two sets of primers located in the conserved $5^{\prime}$ untranslated region as described previously (10). Briefly, RNA was extracted by guanidinium thyocianate from $100 \mu \mathrm{l}$ of serum, retrotranscribed with the HCV external antisense primer 1A (5'-GATGCACGGTCTACGAGACCTC-3'). The cDNA was amplified using the primer $1 \mathrm{~A}$ and the external sense primer 1B (5'-AACTACTGTCTTCACGCAGAA- $\left.3^{\prime}\right) .3 \mu$ of the first PCR products were used for a second round of amplification using an internal antisense primer 2A (5-GCGACCCAACACTACTCGGCT-3') and an internal sense primer 2B (5'-ATGGCGTTAGTATGAGTG-3'). PCR products were analyzed by electrophoresis on $1.5 \%$ agarose gel and stained with ethidium bromide. Two negative control sera were included in each experiment.

Levels of circulating HCV-RNA were measured using the branched-DNA amplification assay, according to the manufacturer's instructions (Quantiplex Version 1.0; Chiron Corp., Emeryville, CA) $(16,17)$. In brief, lysis, hybridization, capture, and signal amplification were carried out on duplicate $50 \mu \mathrm{l}$ serum samples in 96-well plates. A mixture of synthetic oligonucleotides, including probes that mediate capture and probes that bind to the bDNA amplifier molecule were added to the well. This leads to the capture of the HCVRNA molecules onto the surface of the plate and linking of the target to synthetic bDNA molecules. Multiple copies of an alkaline phosphatase-linked synthetic probe hybridize to the immobilized complex thereby amplifying the target signal. Quantitation of HCV-RNA is based on the measure of light emission by a chemiluminescent substrate (dioxetane), which is proportional to the amount of nucleic acid in the sample. The quantity is finally determined by a standard curve and expressed in HCV RNA equivalents per milliliter. The lower limit of sensitivity of this assay is 350,000 genome equivalents $/ \mathrm{ml}$.

$H C V$ genotyping. Genotyping was performed by LIPA assay (Innogenetics, Zwijnaarde, Belgium) in accordance with the manufacturer's instructions. In brief, RNA was extracted by guanidinium thyocianate from $100 \mu \mathrm{l}$ of serum, retrotranscribed with random priming examers (Pharmacia Biothech, Uppsala, Sweden). The cDNA was amplified with an external set of biotin $5^{\prime}$ end-labeled primers derived from the $5^{\prime}$ untranslated region of $\mathrm{HCV} ; 0.2 \mu \mathrm{l}$ of the first PCR products were used for a second round of amplification using an internal set of biotin $5^{\prime}$ end-labeled primers. The PCR products were checked on an agarose gel stained with ethidium bromide to rule out contamination and to ensure adequate products for the reverse-hybridization assay. The PCR products (the first PCR product if showing a clear band on the agarose gel or the nested amplified products) were then denatured before addition of the hybridization buffer and incubation with the genotyping strips for $2 \mathrm{~h}$ at $50^{\circ} \mathrm{C}$. Strips were then stringently washed at $50^{\circ} \mathrm{C}$ for $30 \mathrm{~min}$.

Hybridized PCR products were detected by means of streptavidin-alkaline phosphatase immunochemical staining using NBIP as a substrate. The strips were analyzed, and the genotype assigned according to the pattern of PCR products hybridization (18).

$\mathrm{HCV}$ antigens and peptides. The HCV antigens E1, E2, NS3, NS4, and NS5 were expressed as COOH-terminal fusion proteins with human SOD in yeast (Streptomices cerevisiae) as previously described (10). Purity of the antigen preparations ranged between 85 and $95 \%$. Recombinant SOD and yeast extracts were used in each ex- periment as control for nonspecific proliferation. Antigens were kindly provided by Chiron Corporation.

Synthetic 20-mer peptides overlapping by 10 amino acid residues and covering the entire HCV core and NS4 antigens of genotype 1a (HCV-1 sequence) were purchased from Chiron Mimotopes (Clayton, Australia).

Isolation of PBMC and T cell subsets. PBMC were isolated from fresh heparinized blood by Ficoll-Hypaque density gradient centrifugation. CD4-and CD8-positive $\mathrm{T}$ cell populations were purified by immunomagnetic separation using Dynabeads (Dynal A.S., Oslo, Norway), according to manufacturer's instructions. Briefly, PBMC or antigen-specific T cell lines (see below) were incubated with CD4 or CD8-conjugated magnetic beads at a bead to cell ratio of 3 to 1 for $1 \mathrm{~h}$ at $4^{\circ} \mathrm{C}$ on a rotating platform. Positively selected cells were then recovered by an additional incubation for $1 \mathrm{~h}$ at room temperature with an mAb (Detachabead; Dynal A.S.) competing with CD4 or CD8 antibodies bound to the beads. Isolated cell populations were resuspended at $4 \times 10^{6}$ cells $/ \mathrm{ml}$ in RPMI 1640 supplemented with $25 \mathrm{mM}$ Hepes, $2 \mathrm{mM}$ L-glutamine, $50 \mu \mathrm{g} / \mathrm{ml}$ gentamycin, and $10 \%$ human serum (complete medium).

Production of antigen-specific polyclonal T cell lines. Total PBMC were preincubated for 4-6 h with $\mathrm{HCV}$ antigens at $10 \mu \mathrm{g} / \mathrm{ml}$, then washed and cultured at $3 \times 10^{6} \mathrm{cells} / \mathrm{ml}$ in a 24-well plate. After $5 \mathrm{~d}$, activated $\mathrm{T}$ cells were expanded by adding IL-2. Growing lines were restimulated after an additional $15 \mathrm{~d}$ with irradiated (3,000 Rad) autologous, antigen-prepulsed PBMC $\left(5 \times 10^{5} / \mathrm{ml}\right)$ in medium supplemented with $30 \mathrm{U} / \mathrm{ml}$ recombinant IL-2. From this point, T cell lines were restimulated every $14 \mathrm{~d}$ and provided with supplementary IL-2-containing medium between restimulations to maintain the cell concentration between $3 \times 10^{5}$ and $1 \times 10^{6}(19)$.

Proliferation assays. PBMC $\left(2 \times 10^{5}\right)$ were plated at $50 \mu \mathrm{l} / \mathrm{well}$ in 96-well plates and stimulated with either HCV antigens $(10 \mu \mathrm{g} / \mathrm{ml})$ or control SOD $(10 \mu \mathrm{g} / \mathrm{ml})$ or yeast extracts $(1$ and $0.2 \mu \mathrm{g} / \mathrm{ml})$. To avoid toxic or direct inhibitory effects of the antigen on effector cells, PBMC were washed after 4-6 h, resuspended in complete medium at a final concentration of $10^{6} \mathrm{cells} / \mathrm{ml}$, and cultured in a total vol of 200 $\mu \mathrm{l}$ for $7 \mathrm{~d}$ at $37^{\circ} \mathrm{C}$ in an atmosphere of $5 \% \mathrm{CO}_{2}$ in air.

In selected experiments, unfractionated $\mathrm{T}$ cells $\left(10^{5} /\right.$ well $)$ or purified CD4- or CD8-positive T cells from polyclonal T cell lines $(5 \times$ $10^{4} /$ well) were incubated with autologous irradiated (3,000 Rad) PBMC $\left(10^{5} /\right.$ well $)$ as antigen-presenting cells (APC), prepulsed with antigen, and then washed before coculture with $\mathrm{T}$ cells.

For synthetic peptide stimulation, PBMC $\left(2 \times 10^{5}\right)$ were cultured in $200 \mu \mathrm{l}$ of complete medium in the presence of $2.5 \mu \mathrm{g} / \mathrm{ml}$ of individual peptides for $7 \mathrm{~d}$. PHA stimulation was carried out for $3 \mathrm{~d}$ with different concentrations of the mitogen (1:200, 1:400, 1:800, 1:1,600; PHA-M; Gibco Life Technologies Inc., Gaithersburg, MD). All proliferation assays were performed in triplicate and $\left[{ }^{3} \mathrm{H}\right]$ thymidine $\left({ }^{3} \mathrm{H}\right.$-TdR; $0.5 \mu \mathrm{Ci}$ per well; sp act $2.0 \mathrm{Ci} / \mathrm{mmol}$; Amersham International, Amersham, UK) was added $15 \mathrm{~h}$ before harvesting. The results are expressed as the mean counts per minute of triplicate determinations. The stimulation index was calculated as the ratio between mean counts per minute obtained in the presence and absence of antigen.

Determination of HLA restriction. mAbs recognizing monomorphic determinants of DR (D1-12; IgG2a), DQ1 (BT3/4; IgG1), DQ2 (XIII358/4; IgG2a), DQ3 (XIV466; IgG2b), DP (B7/21; IgG2a), and an mAb anti- HLA A,B,C-specific (W6/32; IgG2a) were a gift from Dr. R.S. Accolla, University of Verona, Italy (19). Irradiated non-T cells as APC $\left(2 \times 10^{4} /\right.$ well $)$ were incubated with $\mathrm{mAbs}$ for $2 \mathrm{~h}$ before addition of antigen. After a further 4-6 $\mathrm{h}$ incubation with antigen, APC were washed and added to responder T cells $\left(10^{5} /\right.$ well $)$. AntiHLA class II mAbs were used at a 1:1,000 final dilution of ascitic fluid; purified W6/32 was used at the concentration of $1 \mu \mathrm{g} / \mathrm{ml}$.

Statistical analysis. Stimulation indexes derived from patients who normalized ALT values and patients with persistently elevated transaminase levels were compared by the Student's $t$ test for unpaired data. Frequencies of significant proliferative $T$ cell responses were compared by $\chi^{2}$ and log-linear analysis. Possible correlations between 
proliferative T cell responses and HCV-RNA levels were assessed by linear regression analysis.

\section{Results}

Clinical outcome. The follow-up of the 21 patients with acute hepatitis $\mathrm{C}$ enrolled into the study (from clinical presentation with symptoms of acute hepatitis and/or transaminase elevation) ranged between 18 and $91 \mathrm{wk}$ (average follow-up $44 \mathrm{wk}$ ). 17 patients were genotyped, and the most prevalent genotype was genotype 1a (8 patients) followed by genotype 3a (5 patients), genotype $1 \mathrm{~b}$ ( 3 patients), and genotype $2 \mathrm{a}$ ( 1 patient) (Table I). 12 of the 21 patients with acute hepatitis $C$ normalized the ALT values (group I); ALT normalization was observed 3-7 wk from clinical presentation, with the exception of a single patient who was coinfected with HBV and normalized ALT values after $18 \mathrm{wk}$, showing a biphasic transaminase peak (patient 4). The remaining 9 patients (group II) showed transaminase levels persistently above the normal range, with the exception of patient 15 (followed $91 \mathrm{wk}$ ) (Table I) who showed a mild activity of disease with continuous ALT fluctuations from normal to slightly elevated values (2-3 times the upper limit), and patient 21 (followed $29 \mathrm{wk}$ ) (Table I) who rapidly normalized ALT levels after a very high transaminase peak at presentation $(3,000 \mathrm{U} / \mathrm{L})$, but relapsed after $4 \mathrm{wk}$ of normal
ALT. ALT levels at presentation were not predictive of the different clinical outcomes.

10 of the 12 patients who normalized ALT showed negative HCV-RNA by nested PCR at the end of the follow-up, while two patients (patients 9 and 12) remained HCV-RNA positive. All patients with elevated ALT were persistently HCV-RNA positive (Table I). Since $\mathrm{HCV}$ can reactivate even after long periods of normal ALT and, on the other hand, clinic and virologic recovery can be observed also late after a protracted liver inflammation, it is clear that definitive conclusions about final diagnosis cannot be drawn for a proportion of patients followed for less than a year (Table I).

Proliferative $T$ cell responses to $H C V$ proteins and peptides. PBMC stimulation with $\mathrm{HCV}$ proteins was carried out every wk during the first mo of disease, every 2 wk during the following 2 mos, and then once a month for the rest of the follow-up. Some time points were missing due to the variable compliance of the patients. An antigen concentration of $10 \mu \mathrm{g} /$ $\mathrm{ml}$ was used based on the results of a previous study (10) showing that optimal levels of proliferative $\mathrm{T}$ cell response were induced by this antigen concentration. PBMC from 12 control $\mathrm{HCV}$-uninfected subjects were serially tested with HCV proteins and peptides to define the levels above which a proliferative response can be considered positive. Based on these results, stimulation index values of 3 and 4 (which correspond to

Table I. Clinical and Virological Characteristics of the Patient Population

\begin{tabular}{cccc}
\hline Patient & Epidemiology & Follow-up & Seroconversion \\
\hline & $w k$ & HCV-RNA
\end{tabular}

Normal ALT*

\begin{tabular}{|c|c|c|c|c|c|}
\hline 1) & Drug & 79 & + & - & nd \\
\hline 2) & Drug & 32 & + & - & $3 a$ \\
\hline 3) & Sexual Exposure & 18 & - & - & $1 b$ \\
\hline 4) & Drug & 71 & + & - & nd \\
\hline 5) & Drug & 33 & + & - & la \\
\hline 6) & Drug & 77 & + & - & nd \\
\hline 7) & Drug & 39 & + & - & la \\
\hline 8) & Sexual Exposure & 25 & + & - & nd \\
\hline 9) & Drug & 57 & + & + & $1 b$ \\
\hline 10) & Drug & 33 & + & - & $1 \mathrm{a}$ \\
\hline 11) & Drug & 29 & + & - & $1 \mathrm{a}$ \\
\hline 12) & Drug & 25 & + & + & $1 \mathrm{a}$ \\
\hline \multicolumn{6}{|c|}{ Elevated $\mathrm{ALT}^{\ddagger}$} \\
\hline 13) & Drug & 53 & - & + & $3 a$ \\
\hline 14) & Drug & 28 & + & + & $1 \mathrm{a}$ \\
\hline 15) & Sexual Exposure & 91 & + & + & $3 a$ \\
\hline 16) & Drug & 47 & + & + & $3 a$ \\
\hline 17) & Needle Stick & 42 & + & + & $1 b$ \\
\hline 18) & Drug & 29 & - & + & $1 \mathrm{a}$ \\
\hline 19) & Drug & 22 & - & + & $1 \mathrm{a}$ \\
\hline 20) & Surgery & 64 & + & + & $2 \mathrm{a}$ \\
\hline 21) & Drug & 29 & + & + & $3 a$ \\
\hline
\end{tabular}

*ALT normalization was observed 3-7 wk from clinical presentation, with the exception of a single patient who was coinfected with HBV and normalized ALT values after 18 wk showing a biphasic transaminase peak (patient 4). ${ }^{\ddagger}$ All patients showed ALT levels persistently above the normal range, with the exception of patient 15 who showed a mild activity of disease with continuous ALT fluctuations from normal to slightly elevated values (2-3 times the upper limit), and patient 20 who normalized ALT levels rapidly following a very high transaminase peak at presentation (3,000 U/ liter), but relapsed after $4 \mathrm{wk}$ of normal ALT. 
the mean plus at least 2 standard deviations of the response to each protein or peptide obtained in the control group) were defined as the upper limit of the normal range for proliferative responses to HCV proteins and peptides, respectively. All results with recombinant proteins were corrected by subtraction of the stimulation index values obtained with control recombinant SOD and yeast extracts. Since a few healthy uninfected controls showed proliferative response to the batch of recombinant core antigen used in this study, data with this recombinant protein will not be illustrated to avoid ambiguity in the interpretation of the results. T cell reactivity to $\mathrm{HCV}$ core was therefore assessed only with synthetic peptides, which never induced significant levels of proliferative response in the control group.

Significant proliferative responses to NS4, NS5, and E2 were observed with similar frequencies in the whole patient population (NS4 29\%, NS5 28\%, E2 28\%), suggesting similar levels of immunogenicity of these antigens at the effector $\mathrm{T}$ cell level. Higher frequencies of significant $\mathrm{T}$ cell responses (43\%) were observed with NS3, whereas only $10 \%$ of E1-specific responses were detected.

To characterize the effector cell population responsive to $\mathrm{HCV}$ proteins, in selected patients, antigen-responsive cells were expanded and kept in continuous culture by PBMC stimulation with antigen and IL-2. As expected, because of the exogenous nature of the antigen used for PBMC stimulation, PBMC responsiveness to antigen was shown to be sustained by HLA class II-restricted, CD4+ T cells, as illustrated in Fig. 1.

When the proliferative responses expressed by patients who succeeded in normalizing ALT and those who maintained persistently elevated transaminase values were analyzed, a clear difference emerged from the comparison of the two groups. Both vigor and frequency of significant responses to E2, NS3, NS4, and NS5 were much greater in group I than in group II. This was evident from the comparison of the peak proliferative responses displayed by individual patients to the different HCV proteins (Fig. 2, bottom of each panel) as well as from the comparison of the frequency of significant responses to individual proteins expressed by each patient during the follow-up (Fig. 2, top of each panel). The sequential analysis of the $\mathrm{T}$ cell response to $\mathrm{HCV}$ proteins in the two groups of patients as a function of the time from clinical presentation, showed that significant values of proliferative responses to E2, NS3, NS4, and NS5 were more frequent in patients who normalized ALT at almost all time points of the follow-up (Fig. 3).

Similarly, the vigor of the T cell responses to E2, NS3, NS4, and NS5 was also significantly greater in group I, as shown by the comparison of all responses to the individual proteins (in terms of stimulation indexes) expressed by the two groups of patients throughout the follow-up (Fig. 4). In contrast, vigor and frequency of significant responses to E1 were similar in the 2 groups of patients. A significant difference between group I and II was observed also with an additional experimental approach based on $\mathrm{T}$ cell stimulation with synthetic 20-mer peptides covering the entire HCV core and NS4 regions $(P<0.001$ for both antigens) (Fig. 5). This difference was highly significant when all determinations derived from all patients of the 2 groups were compared. In particular, while only one of the patients who normalized ALT did not respond to NS4 peptides at the time points analyzed, a complete lack of response was detected in six patients with persistent transaminase elevation. Furthermore, all patients who normalized ALT responded to at least one core peptide, whereas no response to

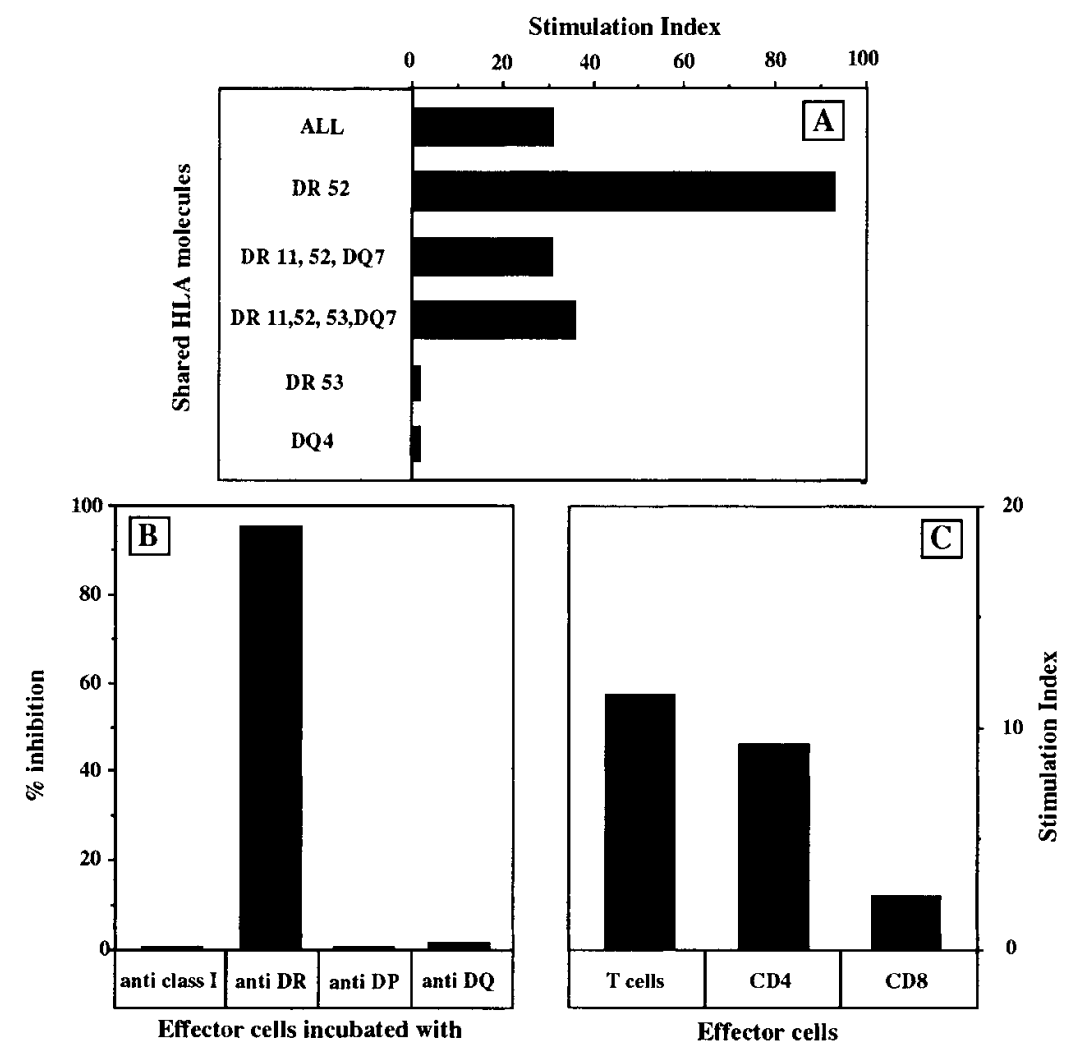

Figure 1. The proliferative response to $\mathrm{HCV}$ antigens is HLA class II restricted and CD4 mediated. Two representative polyclonal T cell lines (one NS5-specific in $A$ and $B$ and one NS4-specific in $C$ ) are illustrated. $(A)$ Proliferative response to NS5 in the presence of totally or partially matched APC; the T cell line derived from patient 2 (HLA DR4, 11, w52, w53, DQ7, 4) recognizes NS5 in association with DRw52. (B) Inhibition of the proliferative response to NS5 (of the same $\mathrm{T}$ cell line illustrated in $A$ ) by anti-HLA DR but not by anti-HLA DQ, anti-DP, or anti-class I mAbs; anti-DQ was a mixture of anti-DQ1, antiDQ2, and anti-DQ3 monoclonals. $(C)$ Proliferative response to NS4 in the presence of irradiated autologous PBMC of unfractionated, $\mathrm{CD} 4+$, or CD8+ T cells purified by immunomagnetic separation from a polyclonal $\mathrm{T}$ cell line derived from patient 2 . Purity of the CD4+ and CD8+ subsets was over $95 \%$. 

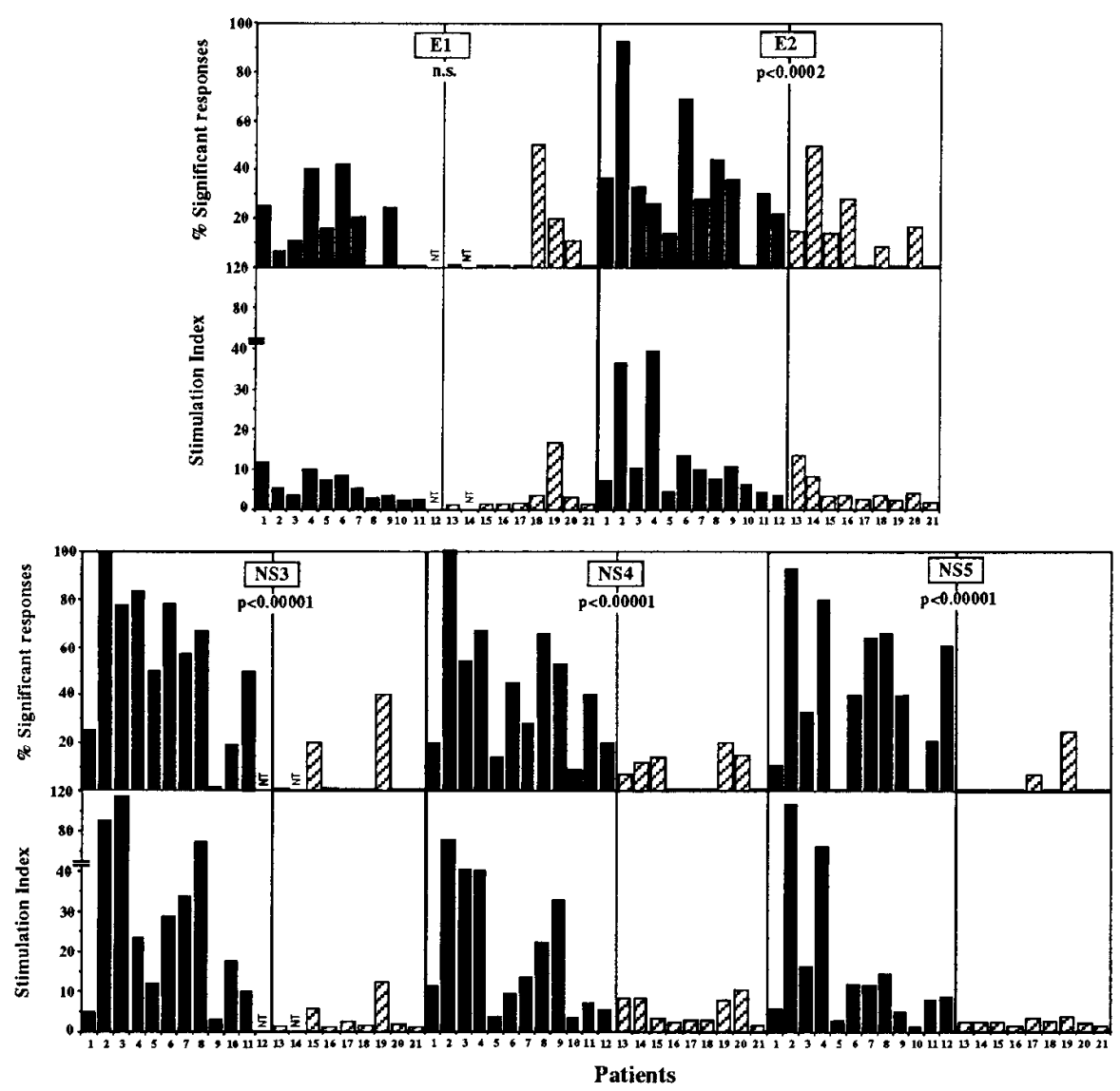

Figure 2. Frequencies and peaks of proliferative $\mathrm{T}$ cell responses to $\mathrm{HCV}$ proteins. The upper part of each panel illustrates the frequencies of significant proliferative responses to HCV antigens expressed by each patient during the whole follow-up; the lower part illustrates the highest level of proliferation displayed by each patient. Frequencies were compared by $\chi^{2}$ analysis. $\mathbf{\square}$, patients who normalized ALT; $\mathbb{Z}$, patients with persistently elevated ALT. core peptides was observed in four patients with persistent liver damage. Finally, a larger number of core and NS4 T cell epitopes were simultaneously recognized by patients who normalized transaminase values compared to the patients with persistently elevated ALT. Only one patient with persistent ALT normalization responded to C22 but not to NS4 peptides during the course of the follow-up; all other patients of this group responded to one or more core and NS4 peptides simul-

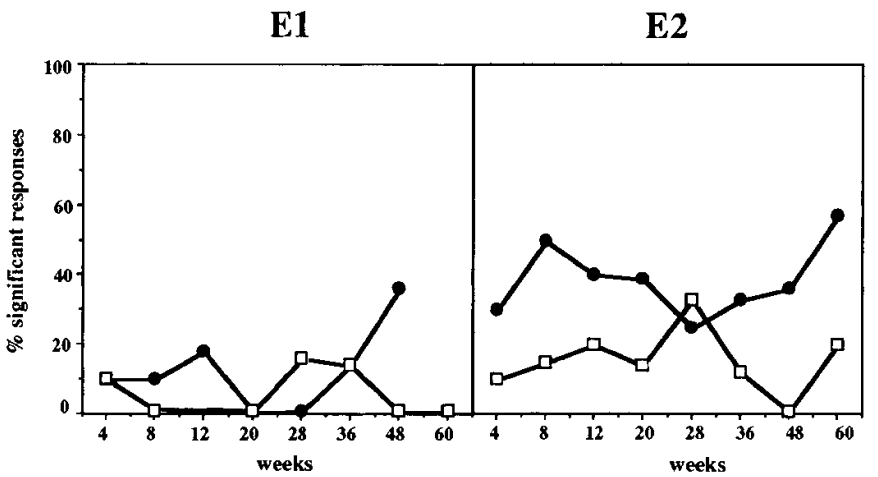

NS3

NS4

NS5

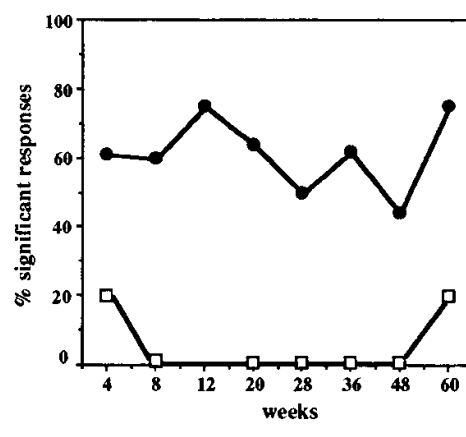

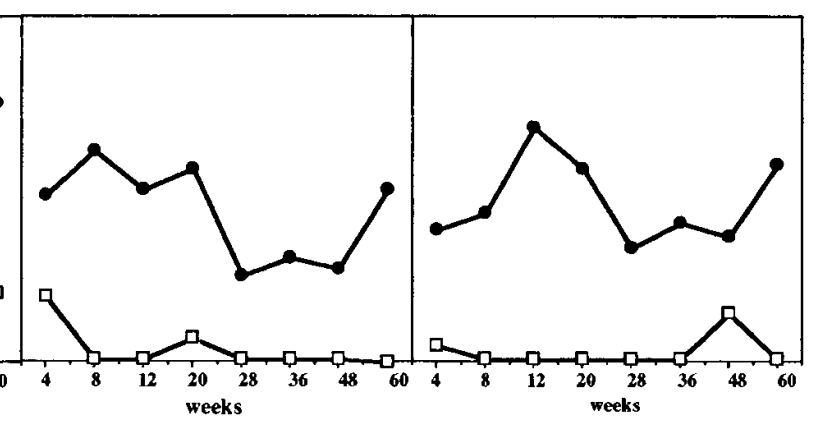

Figure 3. Kinetics of the T cell response to $\mathrm{HCV}$ antigens. The percentage of significant responses at each time point was calculated only when at least four different proliferation assays were available (mean 11 determinations per point). The differences between the two groups were statistically significant by $\log$ linear analysis with respect to the $\mathrm{T}$ cell responses to E2 $(P<0.02)$, NS3 $(P<0.0004)$, NS4 $(P<0.00001)$ and NS5 $(P<0.00001)$ but not E1. -, patients who normalized ALT; $\square$, patients with persistently elevated ALT. 


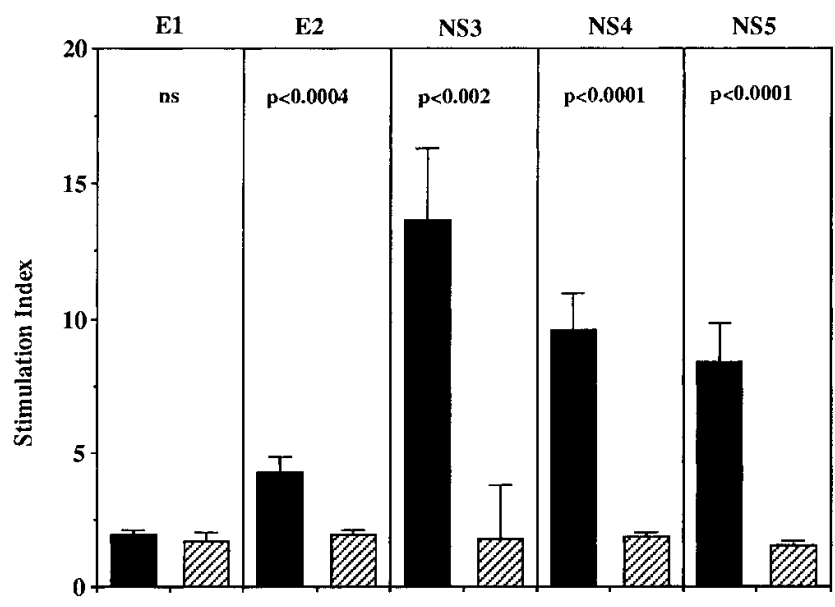

Figure 4. Comparison of the strength of T cell responses to HCV proteins in patients with different outcome of infection. $\mathbf{a}$, patients who normalized ALT; $\mathbb{Z}$, patients with persistently elevated ALT.

taneously. Among the group of patients with persistent ALT elevation, two patients showed sporadic responses to core but not to NS4 peptides, four responded neither to core nor to NS4 peptides, and three patients responded to both. To assess whether the weaker responses to HCV proteins in patients with persistently elevated ALT were due to a general state of $\mathrm{T}$ cell hyporesponsiveness, $\mathrm{T}$ cell proliferative responses to different doses of PHA analyzed sequentially in the two groups of patients during the first 6 mos of follow-up were compared. No statistically significant difference was observed between group I and II (not shown).

$H C V$ viremia and T cell proliferative responses. Patients who normalized ALT transiently or persistently showed either undetectable viremia at the beginning of disease or a rapid fall to negative values by bDNA analysis. While bDNA remained negative in all patients with persistent normalization of ALT, the only two patients who developed a chronic disease after transient ALT normalizations were HCV-RNA negative (by bDNA) at clinical presentation but became bDNA positive later (patients 15 and 20, Tables I and II). All patients with persistently elevated ALT were persistently HCV-RNA positive. An inverse relationship was observed between viremia and $\mathrm{T}$ cell responses, since patients who normalized ALT showed lower viremia and higher levels of $\mathrm{T}$ cell responses to $\mathrm{HCV}$ proteins, whereas patients with persistent liver inflammation showed high viremia and weak T cell responses (Table II). Despite this, a statistically significant correlation could not be demonstrated by linear regression analysis between levels of stimulation index and levels of viremia at the individual points of the follow-up. This is, however, not surprising if one considers that in the interplay between virus and host immune system a given immunologic event needs some time to cause its effect on the virus and vice versa, making highly unlikely the possibility of finding a correlation between virologic and immunologic parameters measured at the same time points.

\section{Discussion}

Acute HCV infection represents an ideal natural model to study the pathogenesis of viral persistence because the high rate of chronic evolution provides the opportunity to follow sequentially from the early stages of infection the immune events associated with recovery from disease or with chronic liver damage and viral persistence.

To assess whether quantitative and/or qualitative differences in the antiviral immune response can account for different outcomes of disease, we have focussed our analysis on the HLA class II-restricted T cell response to HCV antigens because this response is crucial for optimal induction of neutralizing antibodies as well as cytotoxic T cell responses (20). In addition, several lines of evidence indicate that the pattern of cytokines secreted by CD4+ helper T cells can facilitate eradication of infection when it is dominated by $\mathrm{T}$ helper 1 responses or can favor viral persistence if it is oriented toward $\mathrm{T}$ helper 2 effects (21).

Previous studies from our laboratory showed that asymptomatic anti-HCV+ subjects who successfully cleared HCVRNA from serum and PBMC after a previous episode of acute $\mathrm{HCV}$ infection can express vigorous HLA class II-restricted T cell responses to HCV antigens, even several years after resolution of hepatitis (10). T cell responses were stronger than in chronically infected patients, raising the question of whether the relative strength of response can represent a crucial determinant of viral clearance or persistence and whether a quantitative difference in the $\mathrm{T}$ cell response among patients with different outcomes of disease is also present at the early stages of infection, when the crucial pathogenetic events are likely to occur.

To address this important issue a group of patients with acute $\mathrm{HCV}$ infection was selected and studied for the proliferative $\mathrm{T}$ cell response to $\mathrm{HCV}$ proteins sequentially from clinical presentation to the later stages after acute disease. The main finding of our study is the observation that $\mathrm{T}$ cell responses to structural (core and E2) as well as nonstructural (NS3, NS4, and NS5) HCV antigens are more frequently detectable and significantly stronger in the group of patients who normalize the transaminase levels. A difference in the response to NS3, NS4 and NS5 was observed at all time points analyzed. The difference was less striking for E2 (Fig. 3), even if comparison of the average values of all determinations carried out in the two groups throughout the follow-up gave highly significant results (Fig. 4).

The difference between the two groups of patients was evident not only using recombinant proteins to study $\mathrm{T}$ cell responses but also using synthetic peptides. While our results with NS4 peptides cannot be compared with previous data because no information was available so far on the fine specificity of the HLA class II-restricted response to this HCV region, the most immunogenic epitopes of the core antigen reported previously (AA 23-42, 66-85, 131-150) correspond to AA sequences widely recognized in our group of patients (11). Our data are partially in keeping with the results of a recent study showing that the T cell response to NS3 and possibly to the other nonstructural proteins is stronger in patients with selflimited acute infection than in those evolving to chronic hepatitis (15). Our results extend these observations indicating also that the $\mathrm{T}$ cell response to core and $\mathrm{E} 2$ is more vigorous in patients who recover from acute infection. This suggests that the whole HCV-specific T cell response, rather than the response to nonstructural proteins only, is enhanced in self-limited compared to evolving acute hepatitis $\mathrm{C}$. The lack of difference with respect to the response to E1 may be due to the high variabil- 


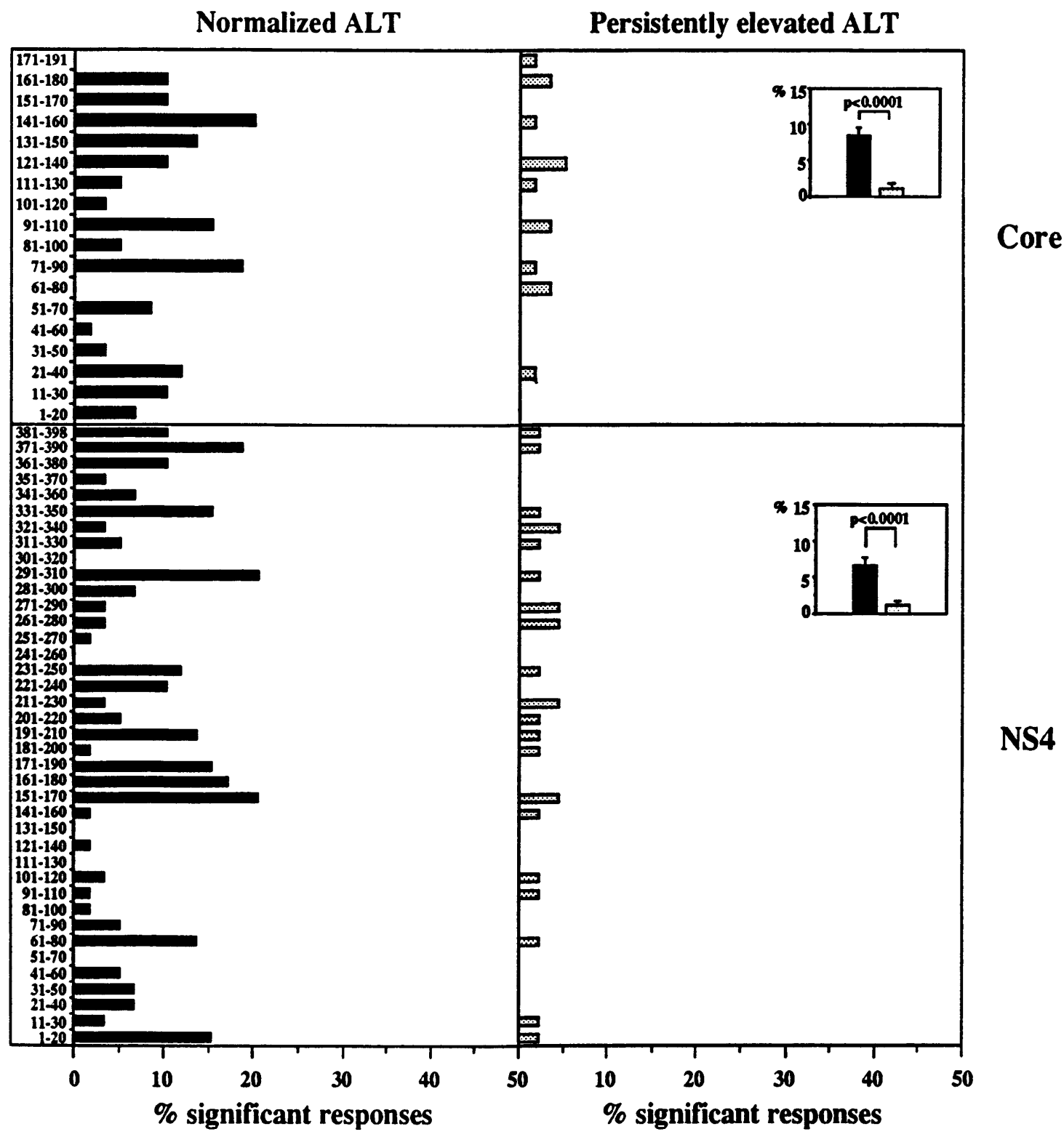

Figure 5. Frequency of significant T cell proliferative responses to core and NS4 synthetic peptides. Values for each peptide were calculated from a total number of 115 determinations for core $(59$ and 56 determinations in patients who normalized and in those with persistently elevated ALT, respectively) and 102 determinations for NS4 (59 and 43 determinations in patients of group I and II, respectively) carried out sequentially during the course of the follow-up. These numbers of determinations derive from the total number of patients tested (21) multiplied by the number of assays carried out throughout the follow-up in each patient. Amino acid sequences of each peptide are indicated by the amino acid position from the $\mathrm{NH}_{2}$ terminus of the core and NS4 proteins. The inserts illustrate the statistical comparison between the percentage of significant responses in patients who normalized and patients who had persistently elevated ALT. $\mathbf{a}$, patients who normalized ALT; $\square$, patients with persistently elevated ALT.

ity of this region combined with its small size (E1 is half of the size of E2).

All these results are consistent with the concept that an efficient and vigorous $T$ cell response at the early stages of infection may be critical to limit the spread of the virus within the infected host and to keep viral replication under control. This may provide the immune system with an important advantage over the virus which may ultimately favor viral clearance over chronic persistence. An efficient immune response able to limit viral spread and replication could also facilitate development of an asymptomatic carriage of the virus with persistence of HCV-RNA in serum but absence of biochemical signs of liver disease, as it may have happened in patients 9 and 12 (Table I). Thus, recovery (ALT normalization with negative HCV-RNA) and asymptomatic carriage (ALT normalization with positive HCV-RNA) may simply represent two different levels of control exerted by the immune system over the virus.

All these interpretations are based upon the assumption that the difference observed in vitro reflects a different vigor of responses mounted in vivo upon viral antigen presentation to the immune system. Although this is the most likely interpretation of our results, it is important to consider that our 
Table II. Frequency of Significant T Cell Responses to HCV Proteins and Levels of Serum HCV-RNA Measured at Different Time Points during Follow-up in a Representative Group of Patients with Persistently Elevated or Normal ALT

\begin{tabular}{lcccr}
\hline & & \multicolumn{3}{c}{$\begin{array}{c}\text { HCV-RNA } \\
\left.\text { (bDNA-Eq/ml } \times 10^{5}\right)\end{array}$} \\
\cline { 3 - 5 } & & \multicolumn{3}{c}{ Month } \\
\cline { 3 - 5 } \multicolumn{1}{c}{ Patient } & $\begin{array}{c}\text { \% Significant } \\
\text { T cell responses }\end{array}$ & $0-1$ & $3-4$ & $6-7$ \\
\hline Normal ALT & & & & \\
2 & 96 & Neg & Neg & n.t. \\
4 & 61 & Neg & Neg & Neg \\
5 & 20 & Neg & Neg & Neg \\
6 & 60 & Neg & Neg & Neg \\
7 & 45 & Neg & Neg & n.t. \\
9 & 37 & Neg & Neg & Neg \\
10 & 20 & Neg & Neg & n.t. \\
11 & 35 & 580 & Neg & n.t. \\
12 & 34 & Neg & Neg & Neg \\
Elevated ALT & & & & \\
13 & 9 & 10.9 & 35.5 & 83.2 \\
14 & 21 & 35.9 & 66.4 & 35.2 \\
$15^{*}$ & 12 & Neg & Neg & Neg \\
16 & 8 & Neg & 9.2 & 9.5 \\
17 & 0 & 15.6 & 24.2 & 25.2 \\
18 & 2 & 11.4 & 4.5 & 8.5 \\
20 & 9 & Neg & 6.1 & 15.2 \\
& & & & \\
\hline & & & & \\
& & & &
\end{tabular}

No statistically significant correlation could be demonstrated by linear regression analysis between levels of stimulation index and levels of viremia at the individual points of the follow-up. *bDNA positive $(13.2$ $\mathrm{Eq} / \mathrm{ml} \times 10^{5}$ ) at $12 \mathrm{mo}$ of follow-up. ${ }^{*}$ Tested also with Quantiplex 2.0. Results were as follows: patient 15 , negative at mo 1 , and 3.5 at mo 7 ; patient 20,2.5 at mo 1 .

study was focused on the peripheral blood compartment which may only partially reflect immune events occurring within the infected liver (12) where HCV-specific T cells may be preferentially present at the acute stage of infection. Therefore, the alternative possibility that weaker peripheral blood $\mathrm{T}$ cell responses associated with chronic evolution are caused by persistent sequestration of $\mathrm{HCV}$-specific T cells within the liver as a result of continuous viral replication and antigen presentation cannot be completely ruled out at present. However, it is of note that the $\mathrm{T}$ cell response of the patients who normalized ALT was significantly stronger already at the early stages of disease (Fig. 3) when both groups of patients had similarly elevated transaminase levels, as expression of acute hepatitis with cellular recruitment within their livers. This finding strongly suggests that the overall anti-viral immune response was actually more efficient in patients who ultimately succeeded in resolving the disease. Unfortunately, this issue cannot be directly addressed because ethical reasons preclude the possibility of obtaining liver tissue from patients with acute $\mathrm{HCV}$ infection.

An additional factor to take into account in the interpretation of the results of our study is the genotype of the infecting virus. In fact, more than $50 \%$ of the patients with persistent liver cell injury were infected by genotype $2 \mathrm{a}$ or $3 \mathrm{a}$, whereas the HCV proteins used to stimulate their T cell responses were derived from genotype 1 , which is the prevalent genotype detected among recovered patients. Thus, the strength of the $\mathrm{T}$ cell response may have been influenced by the degree of homology between the sequence of the infecting virus and that of the proteins used to stimulate in vitro the $\mathrm{T}$ cell response. This interpretation is however contradicted by the evidence that the $\mathrm{T}$ cell response in genotype 1 -infected patients with persistently elevated ALT was not stronger than in the patients of the same group infected by other genotypes (genotypes 2 and 3) (data not shown). Moreover, two additional lines of observations argue against this interpretation. First, E2 was the most frequently recognized protein by $\mathrm{T}$ cells of patients with persistently elevated ALT, even though the variability of this region is the highest among different genotypes. Second, a highly significant difference between groups was also observed with respect to T cell responses to HCV core which is the most conserved HCV antigen. Significant T cell responses observed in acutely infected patients with persistent liver damage (like those described in the present study) were less frequently detectable and less vigorous than the responses previously reported in patients with long lasting chronic HCV infections $(10,13)$. This suggests that $\mathrm{T}$ cell responsiveness to HCV proteins in the peripheral blood compartment may progressively increase as a function of the time of infection. This may be due either to progressive induction of responses to subdominant epitopes as a result of continuous presentation of viral antigens (22) or to a different compartmentalization of T cells in different stages of infection or to recovery of the T cell function after an early stage of T cell hyporesponsiveness. Alternatively, the different strength of responses may reflect different epidemiological and virological features of the populations of patients selected in different studies. While patients with a history of drug addiction were included in this longitudinal study of acute $\mathrm{HCV}$ infection, most of the data previously reported in chronic hepatitis $\mathrm{C}$ came from infections of posttransfusional or sporadic origin less frequently related to drug addiction $(10,13)$.

In conclusion, our study suggests that the relative strength of the T cell response to HCV proteins in the acute phase of hepatitis $\mathrm{C}$ may represent a critical determinant of the final evolution of disease. The defective $T$ cell responses of patients with persistently elevated ALT do not seem to be due to a generalized poor $\mathrm{T}$ cell responsiveness because the general state of T cell reactivity, as indicated by the PHA study, was not significantly different in the two study groups. Even though definitive conclusions about long-term diagnosis cannot be drawn for a proportion of our patients who were followed for less than a year, what our study unequivocally establishes is the concept that a vigorous anti-viral T cell response is associated with the capacity of the host to normalize ALT levels and recover from hepatitis, either transiently or permanently. Therefore, development of a strong $\mathrm{T}$ cell response seems to be essential for disease resolution, even though it might not be sufficient for definitive recovery. Additional studies are needed to understand why some patients can mount efficient $\mathrm{T}$ cell responses able to control viral replication while the same responses are profoundly depressed in other patients. Irrespective of the primary causes of this $\mathrm{T}$ cell hyporesponsiveness, however, early potentiation of the defective responses may represent a rational objective of future therapeutic strategies to decrease the rate of chronic evolution of hepatitis $\mathrm{C}$. 


\section{Acknowledgments}

We thank EuroCetus Italia S.R.L., Milano, Italy for the kind gift of rIL2; Dr. Jean-Paul Bonn, Chiron Diagnostics, Lyon, France, for the kind gift of bDNA assay kits; Prof. Giuliano Sansebastiano, Istituto di Igiene, Università di Parma and Dr. Gian Franco Elia, Divisione Malattie Infettive, Azienda Ospedaliera di Parma, Parma, Italy for statistical analysis.

This work was supported in part by the National Institutes of Health (grant AI-26626), by the Ministry of Universities and Scientific and Technological Research (Italy) (project on Liver Cirrhosis and Viral Hepatitis).

\section{References}

1. Alter, H.J. 1995. To C or not to C: these are the questions. Blood. 85 : 1681-1695.

2. Brillanti, S., M. Foli, S. Gaiani, C. Masci, M. Miglioli, and L. Barbara. 1993. Persistent hepatitis C viraemia without liver disease. Lancet. 341:464-465.

3. Lunel, F. 1994. Hepatitis C virus and autoimmunity: fortuitous association or reality? Gastroenterology. 107:1550-1555.

4. Koziel, M.J., D. Dudley, J. Wong, J. Dienstag, M. Houghton, R. Ralston, and B.D. Walker. 1992. Intrahepatic cytotoxic T lymphocytes specific for hepatitis C virus in persons with chronic hepatitis. J. Immunol. 149:3339-3344.

5. Koziel, M.J., D. Dudley, N. Afdhal, Q.L. Choo, M. Houghton, R. Ralston, and B.D. Walker. 1993. Hepatitis C virus (HCV)-specific cytotoxic T lymphocytes recognize epitopes in the core and envelope proteins of HCV.J. Virol. 67:7522-7532.

6. Kita, H., T. Moriyama, T. Kaneko, I. Harase, M. Nomura, H. Miura, I. Nakamura, Y. Yazaki, and M. Imawari. 1993. HLA B44-restricted cytotoxic T lymphocytes recognizing an epitope on hepatitis $\mathrm{C}$ virus nucleocapsid protein. Hepatology. 18:1039-1044.

7. Shirai, M., H. Okada, M. Nishioka, T. Akatsuka, C. Wychowski, R. Houghten, C.D. Pendleton, S.M. Feinstone, and J.A. Berzofsky. 1994. An epitope in hepatitis $\mathrm{C}$ virus core region recognized by cytotoxic $\mathrm{T}$ cells in mice and humans. J. Virol. 68:3334-3342.

8. Battegay, M., J. Fikes, A.M. DiBisceglie, P.A. Wentworth, A. Sette, E. Celis, and W. Ching. 1995. Patients with chronic hepatitis C have circulating cytotoxic $\mathrm{T}$ cells which recognize hepatitis $\mathrm{C}$ virus-encoded peptides binding to HLA-A2.1 molecules. J. Virol. 69:2462-2470.

9. Cerny, A., J.G. McHutchison, C. Pasquinelli, M.E. Brown, M.A. Brothers, B. Grabsceid, P. Fowler, M. Houghton, and F.V. Chisari. 1995. Hepatitis C virus specific cytotoxic $\mathrm{T}$ cell response: identification of multiple HLA-A2 restricted epitopes. J. Clin. Invest. 95:521-530.

10. Ferrari, C., A. Valli, L. Galati, A. Penna, P. Scaccaglia, T. Giuberti, C.
Schianchi, G. Missale, M.G. Marin, and F. Fiaccadori. 1994. T-cell response to structural and nonstructural hepatitis $\mathrm{C}$ virus antigens in persistent and self-limited hepatitis C virus infections. Hepatology. 19:286-295.

11. Hoffman, RM, H.M. Diepolder, R. Zachoval, F.M. Zwiebel, M.L. Jung, S. Sholz, H. Nitschko, G. Rietmuller, and G.R. Pape. 1995. Mapping of immunodominant $\mathrm{CD} 4+\mathrm{T}$ lymphocyte epitopes of hepatitis $\mathrm{C}$ virus antigens and their relevance during the course of chronic infection. Hepatology. 21:632-638.

12. Minutello, M.A., P. Pileri, D. Unutmaz, S. Censini, G. Huo, M. Houghton, M.R. Brunetto, F. Bonino, and S. Abrignani. 1993. Compartmentalization of T-lymphocytes to the site of disease: intrahepatic CD4+ T-cells specific for the protein NS4 of hepatitis C virus in patients with chronic hepatitis C. J. Exp. Med. 178:17-26.

13. Bottarelli, P., M.R. Brunetto, M.A. Minutello, P. Calvo, D. Unutmaz, A.J. Weiner, Q.L. Choo, J.R. Shuster, G. Kuo, F. Bonino, M. Houghton, and S. Abrignani. 1993. T-lymphocyte response to hepatitis $\mathrm{C}$ virus in different clinical courses of infection. Gastroenterology. 104:580-587.

14. Schupper, H., P. Hayashi, J. Scheffel, S. Aceituno, T. Paglieroni, P.V. Holland, and J.B. Zeldis. 1993. Peripheral blood mononuclear cell responses to recombinant hepatitis $\mathrm{C}$ virus antigens in patients with chronic hepatitis $\mathrm{C}$. Hepatology. 18:1055-1060.

15. Diepolder, H.M., R. Zachoval, R.M. Hoffman, E. Wierenga, T. Santantonio, M.C. Jung, D. Elchenlaub, and G.R. Pape. 1995. Possible mechanism involving T-lymphocyte response to non-structural protein 3 in viral clearance in acute hepatitis C virus infection. Lancet.: 346:1006-1007.

16. Urdea, M.S., J. Kolberg, B.D. Warner, T. Horn, J. Clyne, L. Ku, and J.A. Running. 1990. A novel method for the detection of hepatitis B virus in human serum samples without blotting or radioactivity. In Luminescence Immunoassay and Molecular Applications. K. Van Dyke and R. Van Dyke, editors. CRC Press Boca Raton, FL. 275-291.

17. Urdea, M.S., T. Horn, T.J. Fultz, M. Anderson, J.A. Running, S. Hamren, and D. Ahle. 1991. Branched DNA amplification multimers for the sensitive, direct detection of human hepatitis viruses. Nucleic Acids Research Symposium Series. No. 24. Oxford University Press, Oxford. 197-200.

18. Struyver, L., R. Rossau, A. Wyseur, M. Duhamel, B. Vanderborght, H. Van Heuverswyn, and G. Maertens. 1993. Typing of HCV isolates and characterization of new (sub)types using a line probe assay. J. Gen. Virol. 74:10931102 .

19. Ferrari, C., A. Bertoletti, A. Penna, A. Cavalli, A. Valli, G. Missale, M. Pilli, P. Fowler, T. Giuberti, F.V. Chisari, and F. Fiaccadori. 1991. Identification of immunodominant $\mathrm{T}$ cell epitopes of the hepatitis B virus nucleocapsid antigen. J. Clin. Invest. 88:214-222.

20. Doherty, P.C., W. Allan, and M. Eichelberger. 1992. Roles of $\alpha \beta$ and $\gamma \delta$ T cell subsets in viral immunity. Annu. Rev. Immunol. 10:123-151.

21. Paul, W., and R.A. Seder. 1994. Lymphocyte responses and cytokines. Cell 76:241-251.

22. Lehmann, P.V., T. Forsthuber, A. Miller, and E.E. Sercarz. 1992. Spreading of T-cell autoimmunity to cryptic determinants of an autoantigen. Nature (Lond.). 358:155-157. 